Research Paper

\title{
Mucin 1 promotes tumor progression through activating WNT/ $\beta$-catenin signaling pathway in intrahepatic cholangiocarcinoma
}

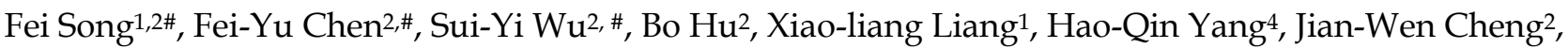 \\ Peng-Xiang Wang2, Wei Guo ${ }^{5}$, Jian Zhou ${ }^{2,6}$, Jia Fan ${ }^{2,6}$, Zhong Chen ${ }^{\bowtie}$, Xin-Rong Yang ${ }^{\circledR}$ \\ 1. Department of Hepatobiliary Surgery, Affiliated Hospital of Nantong University, Nantong 226001, P. R. China; \\ 2. Department of Liver Surgery \& Transplantation, Liver Cancer Institute, Zhongshan Hospital, Fudan University, Key Laboratory of Carcinogenesis and \\ Cancer Invasion, Ministry of Education, Shanghai 200032, P. R. China; \\ 3. Transfusion Department, Zhongshan Hospital, Fudan University, Shanghai 200032, P. R. China; \\ 4. Nanjing Foreign Language School, Nanjing 210018, P. R. China; \\ 5. Department of Laboratory Medicine, Zhongshan Hospital, Fudan University, Shanghai 200032, P. R. China; \\ 6. Institutes of Biomedical Sciences, Fudan University, Shanghai 200032, P. R. China \\ \#These authors contributed equally to this work as first authors.
}

$\square$ Corresponding author: Xin-Rong Yang, MD, PhD, Department of Liver Surgery and Transplantation, Liver Cancer Institute, Zhongshan Hospital, Fudan University, 136 Yi Xue Yuan Road, Shanghai 200032, P. R. China. Email: yang.xinrong@zs-hospital.sh.cn. Zhong Chen, MD, PhD, Department of Hepatobiliary Surgery, Affiliated Hospital of Nantong University, Nantong 226001, P. R. China. Email: chenz9806@163.com.

(C) The author(s). This is an open access article distributed under the terms of the Creative Commons Attribution License (https://creativecommons.org/licenses/by/4.0/). See http://ivyspring.com/terms for full terms and conditions.

Received: 2021.05.27; Accepted: 2021.09.18; Published: 2021.10.03

\begin{abstract}
Background: Current treatment options for intrahepatic cholangiocarcinoma (ICC) are limited by the lack of understanding of the disease pathogenesis. It has been known that mucin 1 (MUCl) is a cell surface mucin that highly expressed in various cancer tissues. However, its role in ICC has not been well studied. The purpose of this study was to investigate the clinical significance and biological function of $\mathrm{MUCl}$ in ICC.

Methods: qRT-PCR and western blot assays were performed to examine MUCl expression. RNA-Seq (RNA Sequencing) s conducted to explore the RNA expression. A tissue microarray study including 214 ICC cases was also conducted to evaluate the clinical relevance and prognostic significance of MUCI. The role and underlying mechanisms of $\mathrm{MUCl}$ in regulating cell growth and invasion were further explored both in vitro and in vivo models.

Results: The mRNA and protein levels of $\mathrm{MUCl}$ were significantly up-regulated in ICC compared to paired non-tumor tissues. Depletion of $\mathrm{MUC1}$ in HCCC9810 cells significantly inhibited cell proliferation, migration and invasion in vitro and overexpression of $\mathrm{MUCl}$ in RBE cells resulted in increased cell proliferation, migration and invasion. Both univariate and multivariate analysis revealed that the protein expression of $\mathrm{MUCl}$ was associated with overall survival and relapse-free survival after tumor resection. Clinically, high $\mathrm{MUCl}$ expression was more commonly observed in aggressive tumors. Further studies indicated that MUCl exerted its function through activating $\mathrm{Wnt} / \beta$-catenin pathway.

Conclusions: Our data suggests that MUCl promoted ICC progression via activating Wnt / $\beta$-catenin pathway. This study not only deciphered the role of MUC in ICC pathogenesis, but also shed light upon identifying novel potential therapeutic targets.
\end{abstract}

Key words: intrahepatic cholangiocarcinoma, mucin $1, \mathrm{Wnt} / \beta$-catenin pathway

\section{Introduction}

Intrahepatic cholangiocarcinoma (ICC) is the second most common primary liver malignancy and often progresses aggressively $[1,2]$. The morbidity and mortality of CC have increased rapidly in recent years
$[3,4]$. Although surgical resection is still the first-line treatment, most patients may already miss the optimal surgical window and even metastasized upon the diagnosis. Currently, no effective chemotherapy 
or targeted molecular therapy has been identified for ICC, mainly due to the insufficient understanding of its pathogenesis.

Mucin (MUC) is the main component in mucus secretion and has unique biophysical and chemical properties due to its nature and glycosylation condition [5,6]. It has been known that MUC can participate in cell regeneration, differentiation, integration, signaling, adhesion, and apoptosis under different conditions $[7,8]$. Human mucins can be divided into two subgroups based on structure, function, and cell localization [9]: membranes (associated with the cell surface) and secreted [10-12]. In the mucin family, MUC1, MUC4, and MUC16 belong to the membrane binding/transmembrane subgroup [7]. Among them, MUC1 has been reported to play a key role as an oncogene in a variety of solid tumors [13-15]. Our previous study showed that the mRNA expression of MUC1 was associated with the prognosis of ICC patients [16]. However, the clinical significance of MUC1 expression at protein level in ICC patients is still needed to further exploration, especially with long-term follow-up and a large number of patients. Moreover, the role of MUC1 in ICC progression has not been clearly defined.

In this study, we explored the expression of MUC1 in human ICC cell lines and tumor tissues by quantitative real-time PCR (qRT-PCR), Western blot analysis and RNA-Seq (RNA Sequencing) analysis. To evaluate the clinical relevance and prognostic significance of MUC1 in ICC, we further examined the expression of MUC1 in tissue microarrays (TMAs) with 214 ICC patients. The completion of this study will not only help us to better understand the pathogenesis of ICC, but also provide insights developing novel therapeutic targets.

\section{Materials and methods}

\section{Patients and specimens}

A total of 30 pairs of snap-frozen ICC samples and matched adjacent non-tumor tissues samples were collected from ICC patients during curative resection in the Liver Cancer Institute, Zhong Shan Hospital, Fudan University in 2019. Among those, 10 pairs were randomly selected for RNA-Seq (RNA Sequencing) analysis, and 8 pairs were selected to detect MUC1 protein expression. Another 12 ICC samples with or without lymph node metastasis for further validation were also randomly selected from the same tissue bank.

Tumor specimens used in tissue microarrays (TMAs) analysis were obtained from 214 consecutive ICC patients who received liver resection in the Liver Cancer Institute, Zhong Shan Hospital, Fudan
University from February 2001 to December 2006. The clinicopathologic characteristics of the 214 ICC patients and $10 \mathrm{mRNA}$-seq patients were summarized in Table $\mathbf{1}$ and Table S1, respectively. Inclusion criteria: 1. Postoperative pathological diagnosis was primary intrahepatic cholangiocarcinoma; 2 . The patient did not undergo any other treatment before surgery. Exclusion criteria: 1. Postoperative pathological diagnosis of patients with hepatocellular carcinoma, extrahepatic cholangiocarcinoma, or non-primary tumors, such as liver metastases of bowel cancer; 2. Patients undergoing chemotherapy, interventional therapy, targeted therapy or immunization before surgery Treatment and other therapeutic. Histopathological diagnosis was made based on World Health Organization criteria, and tumor staging was defined according to the Seven Edition of Tumor-Node-Metastasis (TNM) Classification of International Union against Cancer [17]. Clinical data collection, postoperative follow-up procedures, and admission criteria were performed according to the unified guidelines described in our previous study $[18,19]$. OS was defined as the interval between the date of surgery and the date of death, and RFS was defined as the interval between the date of surgery and the date of tumor recurrence [19]. Ethical approval for human subjects was obtained from the research ethics committee of Zhong Shan Hospital, and informed consent was obtained from each patient. The number of Ethical approval in this study is B2018-018(2).

\section{TMA construction and immunohistochemistry}

Tissue microarray blocks were constructed as described previously [20]. Briefly, all ICC tissues as well as matched adjacent non-tumor tissues were reviewed by two pathologists and representative tumor areas were pre-marked in the paraffin blocks. Two core biopsies of $1 \mathrm{~mm}$ in diameter were taken from the donor blocks and transferred to the recipient paraffin block at defined array positions. Consecutive sections with $4 \mu \mathrm{m}$ thickness were presented on 3aminopropyltriethoxysilane-coated slides (Shanghai Biochip). Immunostaining intensities of these markers were semi-quantitatively scored as follows: 0 , negative; 1 , weak; 2 , moderate; 3 , strong. The score of immunostaining intensity was assessed by two pathologists independently, and comparisons were performed between tumor/normal samples.

\section{Cell lines and transfection}

This study used two human ICC cell lines, HCCC9810 (Shanghai Branch, Chinese Academy of Sciences, Shanghai, China) and RBE (Cell Resource Center, Tohoku University, Japan). Cells were 
maintained in RPMI-1640 plus $10 \%$ fetal bovine serum (Gibco, Big Island, NY, USA) plus penicillin/ streptomycin.

A lentiviral vector encoding wild-type MUC1 was transfected into RBE cells and named RBE-MUC1 cells. RBE-Mock cells transfected with lentiviral vectors only were used as controls. Meanwhile, a lentiviral vector encoding shMUC1 was transfected into HCCC9810 cells and named HCCC9810-shMUC1 cells. HCCC9810-Mock cells transfected with lentiviral vectors only were used as controls. The results of the transfection were verified by qRT-PCR and Western blot analysis.

Table 1. Correlation between $\mathrm{MUCl}$ expression and clinicopathologic characteristics in 214 ICC patients

\begin{tabular}{|c|c|c|c|}
\hline \multirow[t]{2}{*}{ Clinicopathological indexes } & \multicolumn{3}{|c|}{ MUC1 } \\
\hline & Low & High & P value* \\
\hline \multicolumn{4}{|l|}{ Age (year) } \\
\hline$\leq 50$ & 39 & 48 & 0.304 \\
\hline$>50$ & 48 & 79 & \\
\hline \multicolumn{4}{|l|}{ Sex } \\
\hline Female & 30 & 49 & 0.542 \\
\hline Male & 57 & 78 & \\
\hline \multicolumn{4}{|l|}{ HBsAg } \\
\hline Negative & 39 & 77 & 0.023 \\
\hline Positive & 48 & 50 & \\
\hline \multicolumn{4}{|l|}{$\operatorname{AFP}(\mathrm{ng} / \mathrm{ml})$} \\
\hline$\leq 20$ & 58 & 104 & 0.01 \\
\hline$>20$ & 29 & 23 & \\
\hline \multicolumn{4}{|l|}{ CA19-9 (U/ml) } \\
\hline$<37$ & 51 & 48 & 0.003 \\
\hline$\geq 37$ & 36 & 79 & \\
\hline \multicolumn{4}{|l|}{$\operatorname{ALT}(\mathrm{U} / \mathrm{l})$} \\
\hline$\leq 75$ & 73 & 109 & 0.699 \\
\hline$>75$ & 14 & 18 & \\
\hline \multicolumn{4}{|l|}{ Liver cirrhosis } \\
\hline No & 73 & 96 & 0.142 \\
\hline Yes & 14 & 31 & \\
\hline \multicolumn{4}{|l|}{ Tumor size $(\mathrm{cm})$} \\
\hline$\leq 5$ & 47 & 39 & 0.001 \\
\hline$>5$ & 40 & 88 & \\
\hline \multicolumn{4}{|l|}{ Tumor number } \\
\hline Single & 78 & 115 & 0.829 \\
\hline Multiple & 9 & 12 & \\
\hline \multicolumn{4}{|l|}{ Tumor encapsulation } \\
\hline Complete & 21 & 24 & 0.355 \\
\hline None & 66 & 103 & \\
\hline \multicolumn{4}{|l|}{ Lymphatic metastasis } \\
\hline NO & 83 & 96 & 0.000 \\
\hline Yes & 4 & 31 & \\
\hline \multicolumn{4}{|l|}{ Vascular invasion } \\
\hline No & 65 & 111 & 0.017 \\
\hline Yes & 22 & 16 & \\
\hline \multicolumn{4}{|l|}{ Tumor differentiation } \\
\hline I-II & 54 & 92 & 0.109 \\
\hline III-IV & 33 & 35 & \\
\hline \multicolumn{4}{|l|}{ TNM stage } \\
\hline I & 49 & 52 & 0.027 \\
\hline II-III & 38 & 75 & \\
\hline
\end{tabular}

\section{Cell proliferation, cell cycle, migration and invasion assays}

Cell proliferation, cell cycle, migration and invasion assays were performed as previously described [20]. The Cell Counting Kit-8 (Dojindo, Kumamoto, Japan) was used to measure cell proliferation. For the wound-healing assay, a scratch was created across the center of the cell layer using a sterile $100-\mu l$ pipette tip. After $48 \mathrm{~h}$, photographs were taken under the microscope, and cell migration was calculated using Image J software. For matrigel invasion assay, $2 \times 10^{6}$ cells from each group were seeded in the upper chamber of the plate and maintained in FBS-free RPMI 1640 and mitomycin C. The chamber was coated with a matrix gel (1:8 diluted, Corning, ME). RPMI 1640 containing 20\% FBS was added to the lower chamber as a chemoattractant. After $48 \mathrm{~h}$ of incubation, tumor cells that had invaded to the lower surface of the membrane were fixed using $4 \%$ methanol and stained with crystal violet before counting in five random $\times 100$ microscopic fields per sample. Cell cycle was determined by FCM with PI/RNase staining buffer (BD Biosciences). All assays were performed in triplicates and repeated at least twice.

\section{Western blot, and qRT-PCR assays}

Protein was extracted from ICC cells or frozen samples using RIPA buffer and analyzed by Western blot as previously described [21]. Total RNA was extracted using Trizol reagent (Invitrogen, Carlsbad, California, USA), and reverse-transcribed into cDNA using PrimeScript RT kit (Takara, Japan). SYBR Premix Ex Taq ${ }^{\text {TM }}$ (Takara, Japan) was used for qRTPCR according to the manufacturer's instructions, and gene amplification and detection were performed using ABI PRISM 7900 sequence detection system (Applied Bio systems, Foster City, CA, USA).

\section{In vivo assays}

Male non-obese diabetic severe combined immunodeficiency (NOD/SCID) mice (4 weeks old) were purchased from the Shanghai Institute of Material Medicine of the Chinese Academy of Sciences and raised under conditions free of specific pathogens. HCCC9810-shMUC1, HCCC9810-Mock, RBE-MUC1 and RBE-Mock cells $\left(5 \times 10^{6}\right)$ were suspended in $200 \mu \mathrm{l}$ of serum-free RPMI-1640 and Matrigel (BD biosciences; 1: 1) and injected subcutaneously into the small Ventral side of the mice. The tumor volume was measured every three days with a caliper and documented in $\mathrm{mm}^{3}$. At the end of the experiment, the tumors were collected from the model and measured. Animal care and experimental procedures were performed in 
accordance with guidelines developed by the Shanghai Medical Laboratory Animal Care Committee. The entire animal experiment was ethically approved by the Research Ethics Committee of Zhongshan Hospital.

\section{RNA-Seq analysis}

The total RNA was extracted using the RNeasy kit (Qiagen, Hilden, Germany) according to the manufacturer's instructions. RNA was quantified using the Qubit ${ }^{\circledR}$ RNA HS Assay Kit by Qubit ${ }^{\circledR} 2.0$ Fluorometer (Life Technologies, Grand Island, NY, USA). RNA quality was determined using an Agilent 2100 bioanalyzer (Agilent Technologies, Palo Alto, CA, USA). RNA-seq library construction for Next-generation sequencing and paired-end deep sequencing was performed on an Illumina PE150 platform (Illumina, San Diego, CA), according to the manufacturer's protocol.

\section{Statistical analysis}

Statistical analysis was performed using SPSS version 23.0 and GraphPad Prism 7.0. The $x^{2}$ test or Fisher's exact test was used to compare the categorical data, and the Student's t test or one-way analysis of variance was used to analyze the quantitative data. The Kaplan-Meier method was used to plot the OS and RFS curves and compared using a log-rank test. Cox proportional hazard regression models were used for univariate and multivariate analysis. A twotailed $\mathrm{P}$ value of $<0.05$ was considered statistically significant. The complete dataset is available as NGDC proles on the NGDC (National Genomics Data Center) database (https://ngdc.cncb.ac.cn/search/ ?dbId=bioproject\&q=PRJCA005304).

\section{Results}

\section{MUCI was up-regulated in human ICC tissues and associated with lymphatic metastasis}

To explore the potential role of MUC1 in ICC, we first evaluated the mRNA expression of MUC1 in 30 pairs of ICC samples and matched non-tumor liver tissues. The results showed that in $90 \%(27 / 30)$ of all pairs, the MUC1 mRNA expression was significantly up-regulated in ICC tissues compared to adjacent non-tumor liver tissues $(\mathrm{P}=0.039)$ (Figure 1A). Western blot analysis performed on 8 paired ICC tumors and adjacent non-tumor liver tissues showed similar results (Figure 1B). Compared with other types of tumors, lymphatic metastasis is more common in ICC and is an important indicator for poor prognosis [22]. Therefore, we further analyzed the expression of MUC1 in another 12 ICC samples with lymphatic metastasis $(n=6)$ or without lymphatic metastasis $(n=6)$ and found that the mRNA and protein levels of MUC1 were significantly higher in ICC cases with lymphatic metastasis compa red to those without lymphatic metastasis (protein levels $\mathrm{P}$ value $=0.003$; $\mathrm{mRNA}$ levels $\mathrm{P}$ value $=0.002$; Figure 1D).

\section{High expression of MUCI was associated with aggressive clinicopathological characteristics and poor prognosis after tumor resection}

Tissue Microarray analysis (TMA) assay was further performed to detect MUC1 expression in ICC. Immunohistochemical data showed that MUC1 was rated as strong or moderate expression in 59.3\% $(127 / 214)$ of tumor tissues and $22.9 \%(49 / 214)$ in the corresponding adjacent normal intrahepatic bile duct tissue (Figure 1C). In order to explore the clinical significance of MUC1 in ICC, all 214 ICC patients were divided into MUC1 low (score negative or weak, $\mathrm{n}=87$ ) and MUC1 high (score moderate or strong, $\mathrm{n}=$ 127) groups based on immunohistochemical data. The high expression of MUC1 was significantly associated with the level of CA19-9 ( $\mathrm{P}<0.05)$, AFP ( $<<0.05)$, and more aggressive tumor phenotypes including larger tumor size $(\mathrm{P}<0.05)$, presence of lymph node metastases $(\mathrm{P}<0.05)$, vascular infiltration $(\mathrm{P}<0.05)$, and advanced TNM stage $(\mathrm{P}<0.05)$ (Table 1$)$. High expression of MUC1 was also associated with OS and RFS after surgery $(\mathrm{P}=0.002$ for $\mathrm{OS}, \mathrm{P}=0.005$ for RFS; Figure 1E). The median OS and RFS of patients in the MUC1 high group were significantly shorter than those in the MUC1 low group (OS, 16 vs. 29 months, $\mathrm{P}<0.01$; RFS, 16 vs. 35 months, $\mathrm{P}<0.01)$. Multivariate analysis including all variables identified in Cox proportional hazard regression model further confirmed that the high expression of MUC1 was an independent prognostic factor for OS (hazard ratio $[\mathrm{HR}]=1.59$, 95\% confidence interval [CI] 1.14-2.21, $\mathrm{P}=0.006)$ and RFS (HR $=1.67,95 \%$ CI 1.14-2.44, $\mathrm{P}=0.009$ ) (Table 2).

Furthermore, the predictive value of MUC1 was similar among patients with low recurrent risk, such as CA199 level $<37 \mathrm{U} / \mathrm{ml}$, tumor size $\leq 5 \mathrm{~cm}$, without lymphatic metastasis, without vascular invasion and TNM stage I (Figure S1).

\section{Up-regulation of MUCl promoted cell proliferation and invasion in vitro}

To better understand the role of MUC1 in ICC pathogenesis, RBE cells were transfected with a lentiviral vector encoding wild-type MUC1 to over express the MUC1. On the other hand, HCCC9810 cells were transfected with a lentiviral vector encoding a short hairpin MUC1 (shMUC1) to decrease the MUC1 expression (Figure 2A). qRT-PCR and Western blot (Figure 2A) were used to confirm the efficiency of the transfection. 


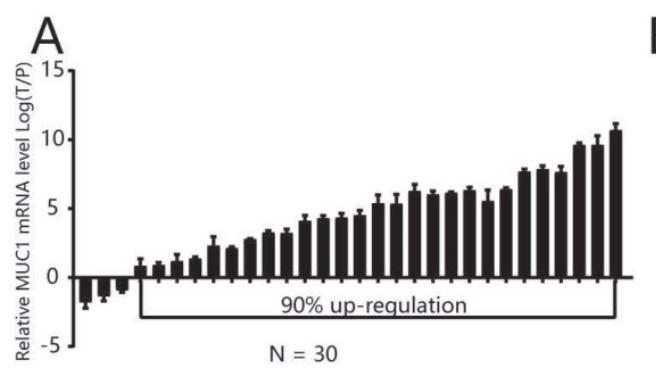

B
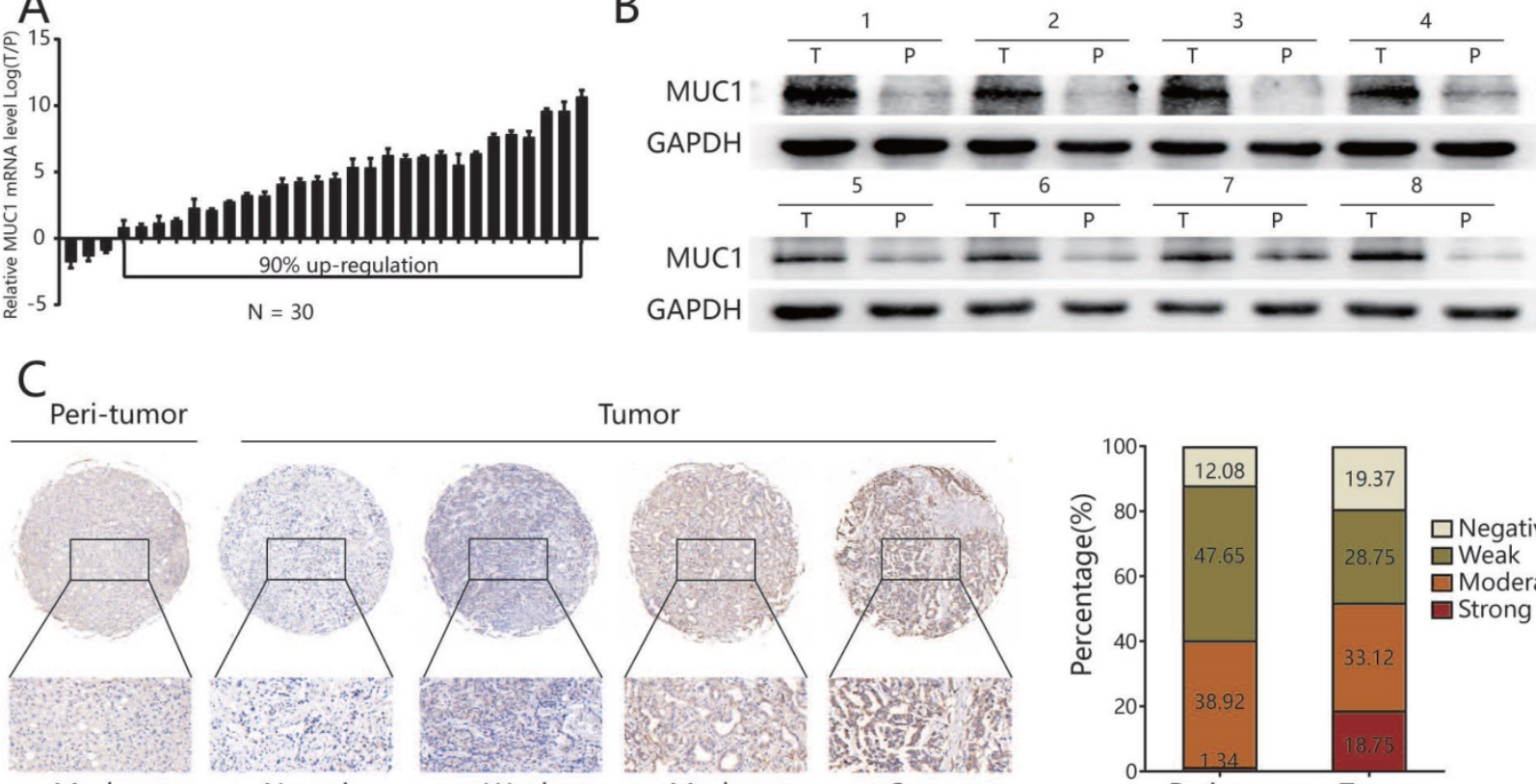

Moderate
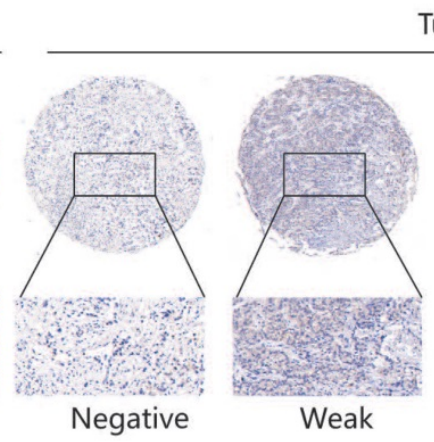

Tumor

D
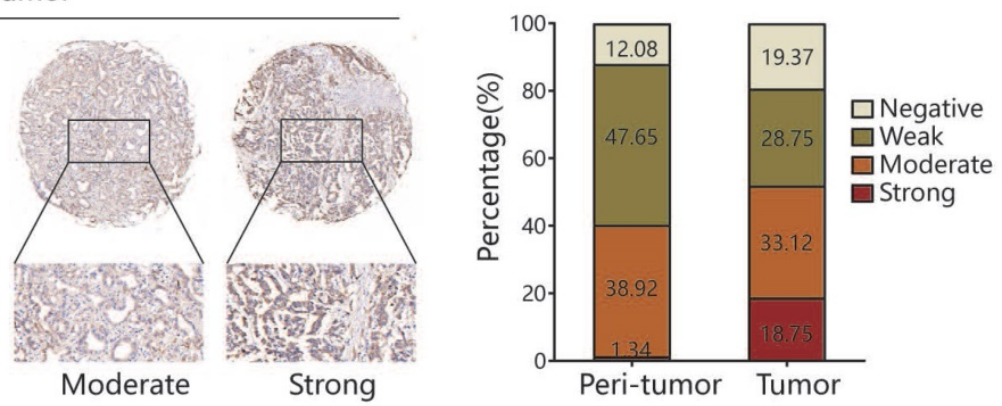

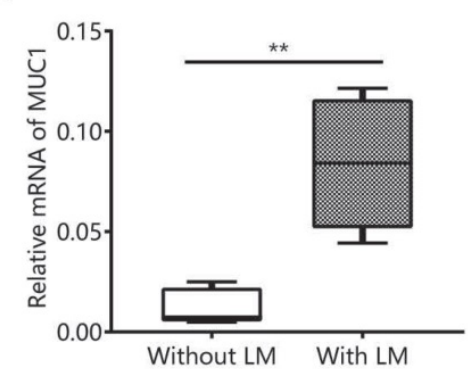

Without LM

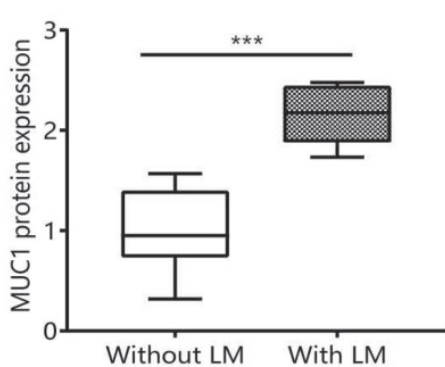

With LM

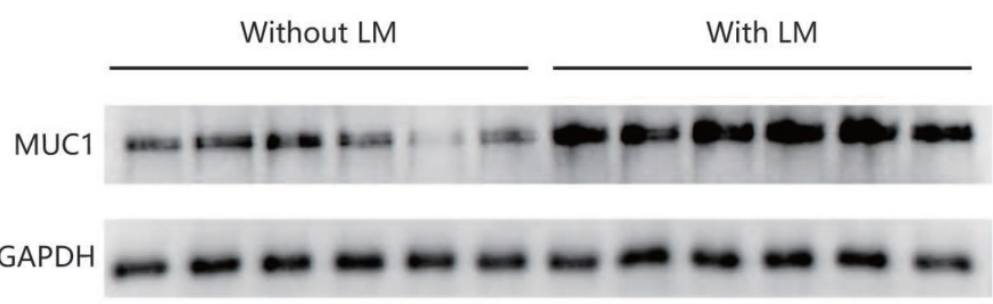

E
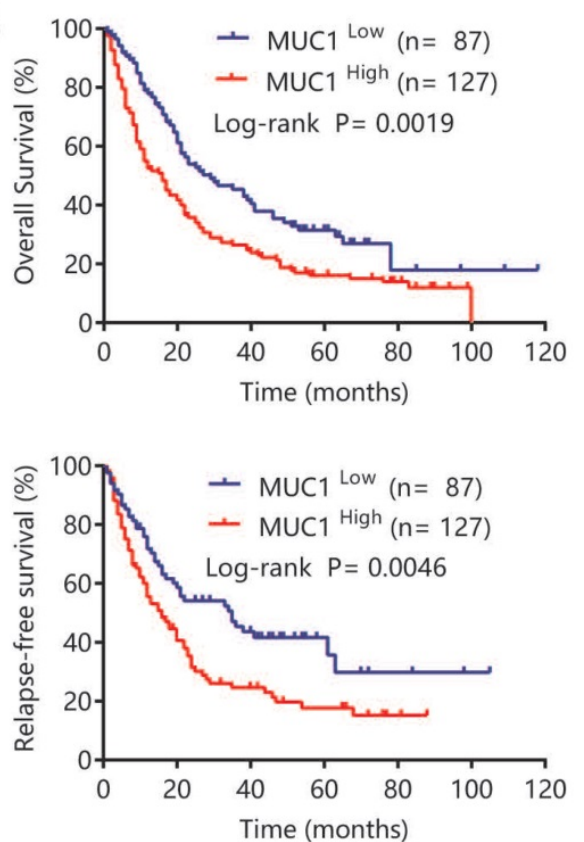

Figure 1. MUC1 was up-regulated in human ICC tissues and associated with lymphatic metastasis. A. The mRNA expression of MUCI in 30 paired ICC tumor and adjacent non-tumor tissues. B. The protein expression of MUC1 in 8 paired ICC tumor $(T)$ and adjacent non-tumor tissues (P). C. Representative immunostaining images of $\mathrm{MUCl}$ in ICC and adjacent nontumor tissues. Left: adjacent non-tumor tissues. Right: different staining intensities in ICC. Bar graph showed the results for the staining intensity of MUC1 in tissue microarrays containing 214 ICC patients. D. The mRNA expression and protein expression of MUC1 in ICC with lymphatic metastasis and without lymphatic metastasis. Densitometry analysis for $\mathrm{MUCl}$ was expressed relative to the loading control, GAPDH. E. Kaplan-Meier curves for overall survival and relapse-free survival of ICC patients according to the expression of MUC1. All bar graphs depicted quantification of triplicate results with mean $\pm S D$, $* * P<0.01$, *** $P<0.001$.

In the proliferation analysis, down-regulation of MUC1 in HCCC9810 cells resulted in a significant inhibition of tumor cell proliferation potential $(\mathrm{P}<$ 0.001 , Figure 2B and 2C). In contrast, the proliferation of RBE-MUC1 cells was significantly enhanced compared to controls ( $\mathrm{P}<0.001$, Figure $2 \mathrm{~B}$ and $2 \mathrm{C}$ ). Further cell cycle analysis showed that knocking down MUC1 expression in HCCC9810 cells significantly reduced the ratio of tumor cells in $S$ phase. In contrast, a significant increase in cell cycle progression from G1 to $S$ phase was observed in RBE cells overexpressed MUC1 (Figure 2D). In addition, both wound-healing analysis and Matrigel invasion analysis indicated that the mobility and invasion capacity significantly decreased in HCCC9810 cells after MUC1 knockdown while increased in RBEMUC1 cells after MUC1 overexpression (Figure 2E and $2 \mathrm{~F}$ ). 
Table 2. Univariate and multivariate analysis of prognostic factors in 214 ICC patients

\begin{tabular}{|c|c|c|c|c|}
\hline \multirow[t]{2}{*}{ Variables } & \multicolumn{2}{|l|}{ OS } & \multicolumn{2}{|l|}{ RFS } \\
\hline & $\mathrm{HR}(95 \% \mathrm{CI})$ & $\begin{array}{l}\mathrm{P} \\
\text { value }\end{array}$ & HR $(95 \%$ CI) & $\begin{array}{l}\mathrm{P} \\
\text { value }\end{array}$ \\
\hline \multicolumn{5}{|l|}{ Univariate analysis } \\
\hline $\begin{array}{l}\text { Age (year) } \\
(>50 \text { versus } \leq 50)\end{array}$ & $1.016(1.002-1.030)$ & 0.023 & 1.010 (0.994-1.027) & 0.217 \\
\hline $\begin{array}{l}\text { Sex (male versus } \\
\text { female) }\end{array}$ & $1.259(0.917-1.728)$ & 0.155 & $1.477(1.005-2.169)$ & 0.047 \\
\hline $\begin{array}{l}\text { HBsAg (positive } \\
\text { versus negative) }\end{array}$ & $0.876(0.670-1.146)$ & 0.335 & $0.979(0.704-1.360)$ & 0.898 \\
\hline $\begin{array}{l}\mathrm{AFP}(\mathrm{ng} / \mathrm{ml}) \\
(>20 \text { versus } \leq 20)\end{array}$ & $1.000(1.000-1.000)$ & 0.701 & $1.000(1.000-1.000)$ & 0.007 \\
\hline $\begin{array}{l}\text { CA19-9 }(\mathrm{U} / \mathrm{ml}) \\
(\geq 37 \text { versus }<37)\end{array}$ & $1.000(1.000-1.000)$ & 0.000 & $1.000(1.000-1.000)$ & 0.001 \\
\hline $\begin{array}{l}\text { ALT }(\mathrm{U} / \mathrm{L}) \\
(>75 \text { versus } \leq 75)\end{array}$ & $1.001(0.999-1.004)$ & 0.261 & $1.002(1.000-1.005)$ & 0.108 \\
\hline $\begin{array}{l}\text { Liver cirrhosis } \\
\text { (yes versus no) }\end{array}$ & $1.023(0.653-1.602)$ & 0.922 & $1.051(0.620-1.780)$ & 0.854 \\
\hline $\begin{array}{l}\text { Tumor size }(\mathrm{cm}) \\
(>5 \text { versus } \leq 5)\end{array}$ & 1.069 (1.019-1.121) & 0.007 & 1.095 (1.034-1.159) & 0.002 \\
\hline $\begin{array}{l}\text { Tumor number } \\
\text { (multiple versus } \\
\text { single) }\end{array}$ & $1.072(0.842-1.366)$ & 0.572 & $0.957(0.664-1.380)$ & 0.815 \\
\hline $\begin{array}{l}\text { Tumor encapsulation } \\
\text { (none versus } \\
\text { complete) }\end{array}$ & $1.742(1.178-2.576)$ & 0.005 & $2.037(1.262-3.288)$ & 0.004 \\
\hline $\begin{array}{l}\text { Lymphatic metastasis } \\
\text { (yes versus no) }\end{array}$ & 2.461 (1.729-3.503) & 0.000 & $2.127(1.367-3.308)$ & 0.001 \\
\hline $\begin{array}{l}\text { Vascular invasion } \\
\text { (yes versus no) }\end{array}$ & 1.151 (1.038-1.277) & 0.008 & $1.124(0.996-1.268)$ & 0.059 \\
\hline $\begin{array}{l}\text { Tumor differentiation } \\
\text { (III-IV versus I-II) }\end{array}$ & $1.016(0.896-1.152)$ & 0.808 & $1.018(0.876-1.183)$ & 0.819 \\
\hline $\begin{array}{l}\text { TNM stage } \\
\text { (II + III versus I) }\end{array}$ & 1.441 (1.121-1.853) & 0.004 & $1.037(0.756-1.422)$ & 0.823 \\
\hline $\begin{array}{l}\text { MUC1 } \\
\text { (low versus high) }\end{array}$ & $1.652(1.208-2.259)$ & 0.002 & $1.655(1.138-2.405)$ & 0.008 \\
\hline \multicolumn{5}{|l|}{ Multivariate analysis } \\
\hline $\begin{array}{l}\text { Age (year) } \\
(>50 \text { versus } \leq 50)\end{array}$ & NA & NA & NA & NA \\
\hline $\begin{array}{l}\text { CA19-9 }(\mathrm{U} / \mathrm{ml}) \\
(\geq 37 \text { versus <37) }\end{array}$ & $1.000(1.000-1.000)$ & 0.000 & $1.000(1.000-1.000)$ & 0.003 \\
\hline $\begin{array}{l}\text { Tumor size }(\mathrm{cm}) \\
(>5 \text { versus } \leq 5)\end{array}$ & NA & NA & NA & NA \\
\hline $\begin{array}{l}\text { Tumor encapsulation } \\
\text { (none versus } \\
\text { complete) }\end{array}$ & NA & NA & 1.899 (1.162-3.106) & 0.011 \\
\hline $\begin{array}{l}\text { Lymphatic metastasis } \\
\text { (yes versus no) }\end{array}$ & 2.105 (1.426-3.107) & 0.000 & NA & NA \\
\hline $\begin{array}{l}\text { Vascular invasion } \\
\text { (yes versus no) }\end{array}$ & NA & NA & $1.726(1.095-2.719)$ & 0.019 \\
\hline $\begin{array}{l}\text { TNM stage } \\
\text { (II + III versus I) }\end{array}$ & NA & NA & NA & NA \\
\hline $\begin{array}{l}\text { MUC1 } \\
\text { (low versus high) }\end{array}$ & $1.587(1.140-2.209)$ & 0.006 & $1.665(1.135-2.443)$ & 0.009 \\
\hline \multicolumn{5}{|c|}{$\begin{array}{l}\text { Cox proportional hazards regression model. Variables for multivariate analysis } \\
\text { were adopted for their prognostic significance by univariate analysis }(\mathrm{P}<0.05) \text {, and } \\
\text { these variables were assessed for prognostic significance by univariate analysis } \\
\text { with forward stepwise selection (forward, likelihood ratio); }\end{array}$} \\
\hline HR hazard ratio, $95 \%$ & $95 \%$ confidence int & 1, A & a-fetoprotein, CA1 & \\
\hline
\end{tabular}

\section{Up-regulation of MUCl promoted ICC progression in vivo}

Subsequently, a mouse subcutaneous xenograft model was developed to evaluate the effect of MUC1 on ICC progression in vivo. The tumor growth curve showed that tumors from HCCC9810-Mock and RBE-
MUC1 cells grew significantly faster than tumors from HCCC9810-shMUC1 and RBE-Mock cells during the same period, respectively (Figure 3A, 3B). The tumor volumes of xenografts derived from HCCC9810-Mock and RBE-MUC1 cells were $376.3 \pm$ 35.92 and $125.7 \pm 11.75 \mathrm{~mm}^{3}$, respectively, which were significantly larger than those of HCCC9810-shMUC1 and RBE-Mock cells $(217 \pm 9.572$ and $53.97 \pm 5.058$ $\mathrm{mm}^{3}$, all $\mathrm{P}$ value $<0.01$ ). Similarly, the weight of tumors derived from HCCC9810-Mock and RBEMUC1 cells xenografts was significantly heavier than that of tumors derived from HCCC9810-shMUC1 and RBE-Mock cells, respectively (Figure $\mathbf{3 A}$ and $3 \mathrm{~B}$ ). Taken together, these results indicated that the expression of MUC1 could promote tumor gross.

\section{MUCI regulated tumor cell proliferation, cell cycle progression, and invasive potential through the $W n t / \beta$-catenin signaling pathway}

To further explore the potential mechanism of MUC1 in promoting tumor progression, we used RNA-seq assay to identify the transcription differences of 10 pairs of ICC patients' tumor tissues and adjacent tissues. As indicated by the qRT-PCR and West blot analysis, the mRNA expression level of MUC1 was significantly higher in tumor tissues compared with the adjacent tissues (Figures 4A). We further performed Gene Set Enrichment Analysis (GSEA) using Kyoto Encyclopedia of Genes and Genomes (KEGG) projects on the 10 pairs of ICC patients' tumor tissues and adjacent tissues, and found that the Wnt signaling pathway was significantly enriched (Figure 4B). Moreover, we found that the enrichment of Wnt signaling pathway was more prominent in high MUC1 group compared to low MUC1 group (FDR $=0.256, \mathrm{P}=0.008$, Figure 4C). It has been known that $\beta$-catenin is an indispensable protein in the Wnt signaling pathway $[23,24]$. Therefore, we further investigated the association between $\beta$-catenin and MUC1 expression in mRNA sequencing samples (Figure S2). Consistently, we observed significant differences in the expression of $\beta$-catenin mRNA between MUC1 Low group and MUC1 High group $(0.64 \pm 0.11$ vs. 1.68 \pm 0.33 , respectively, $P=0.02$ ). Further western blot analysis indicated that the expression level of $\beta$-catenin was significantly down-regulated in HCCC9810 after the inhibition of MUC1 expression, significantly up-regulated in RBE cells after overexpression of MUC1. Meanwhile, the expressions of key downstream target genes among the Wnt/ $\beta$-catenin signal pathway such as Cyclin D1, c-Myc and MMP-7 [25-27] were also explored. We found that the expression of Cyclin D1, c-Myc and MMP-7 was significant down-regulated in HCCC9810 
after the inhibition of MUC1 expression, while these proteins were significantly up-regulated after overexpression of MUC1 in RBE cells (Figure 4D, 4E).
In summary, these results suggested that MUC1 plays an important role in ICC progression by activating the Wnt/ $\beta$-catenin signaling pathway (Figure 5).
A

C

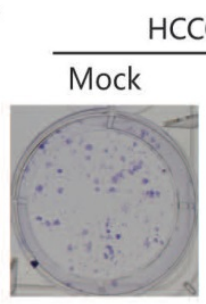

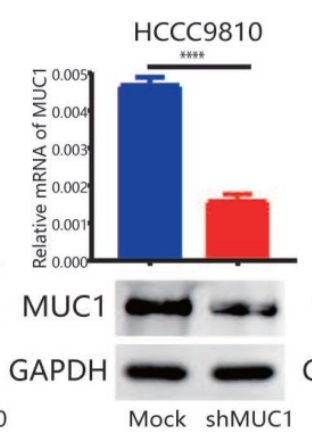

Mock shMUC
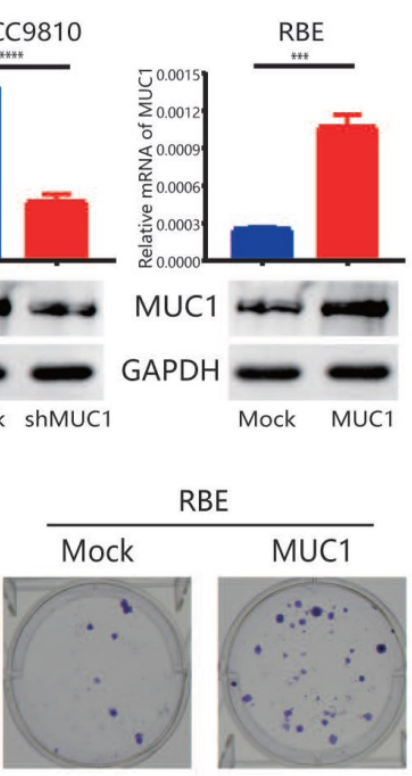

D
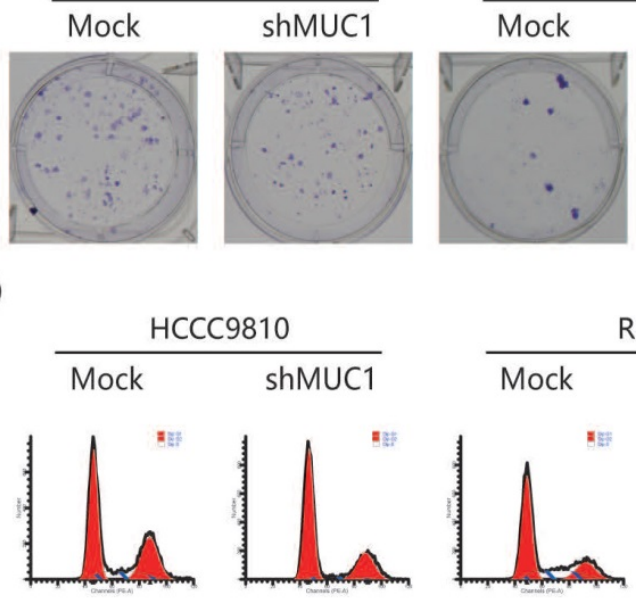

shMUC1

$E$
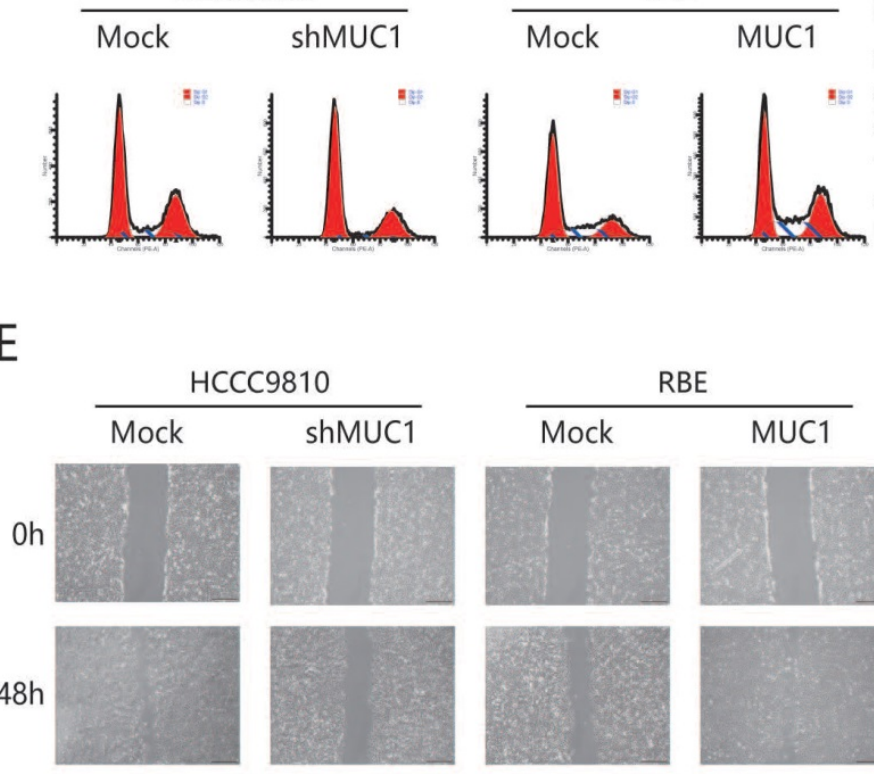

B

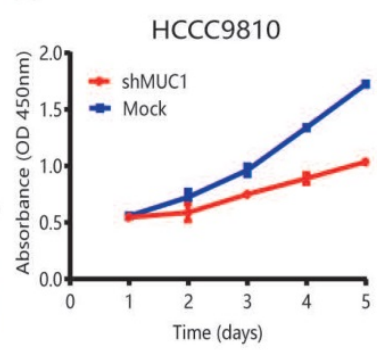

HCCC 9810
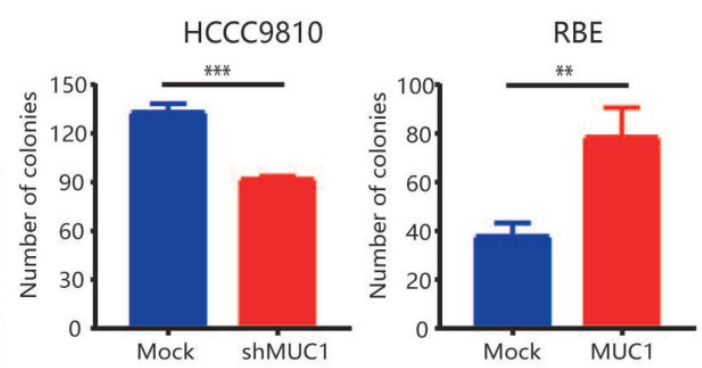

RBE

RBE
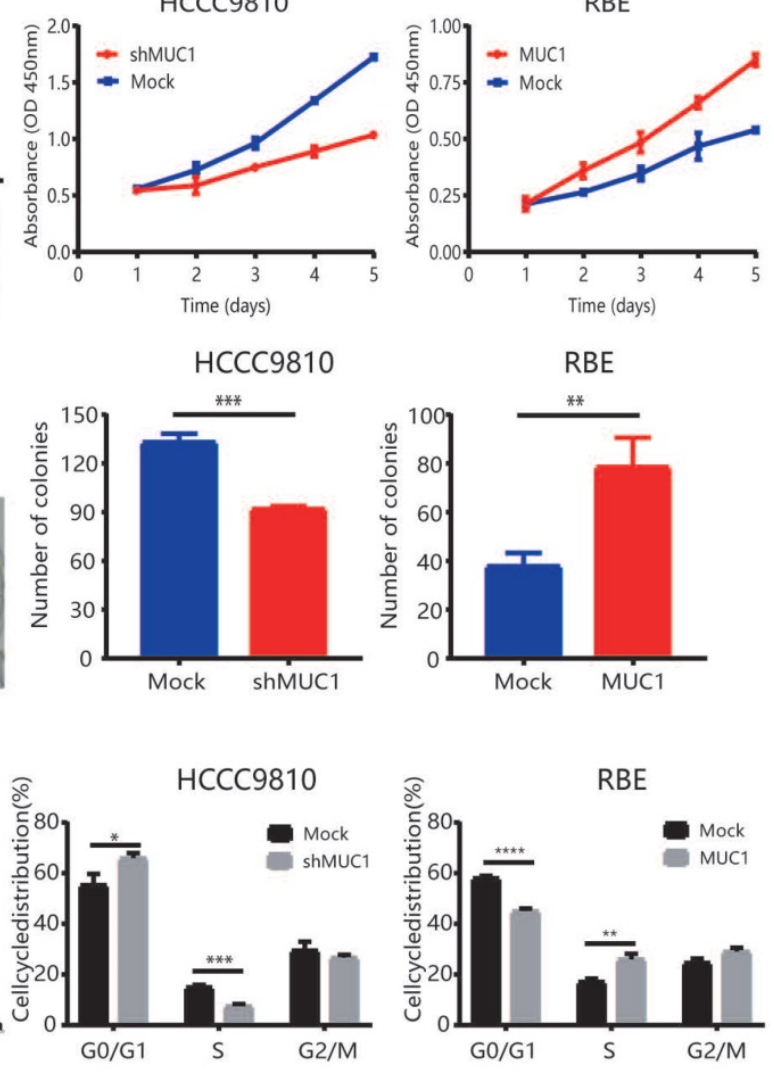

$\mathrm{F}$
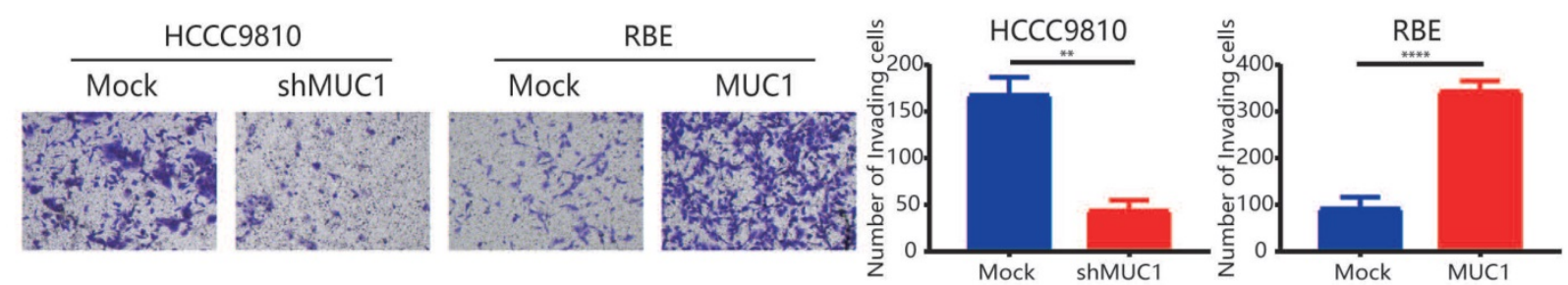

Figure 2. Up-regulation of MUC1 promoted proliferation, cell cycle progression, and invasion of ICC in vitro. A. The mRNA expression and protein expression of $\mathrm{MUCl}$ in ICC cell lines (HCCC9810, RBE, HCCC9810-Mock, HCCC9810-shMUCl, RBE-Mock, and RBE-MUCl). B. Effects of MUCl overexpression and down-regulation on proliferation using Cell Counting Kit-8 kit assay. C. Representative images of the clone formation assay. D. Representative images of MUCl overexpression and down-regulation on cell cycle progression using flow cytometry after propidium iodide staining. E. Representative images of MUC1 overexpression and down-regulation on migration using scratch wound healing assay. Scale bars $=200 \mu \mathrm{m}$. F. Representative images of MUCl overexpression and down-regulation on invasion using Matrigel invasion assay. Scale bars $=100 \mu \mathrm{m}$. All bar graphs depicted quantification of triplicate results with mean $\pm \mathrm{SD}, * \mathrm{P}<0.05, * * \mathrm{P}<0.01, * * * \mathrm{P}<0.001$. 


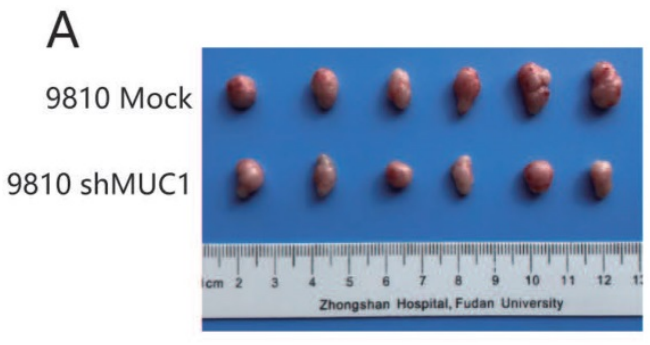

B

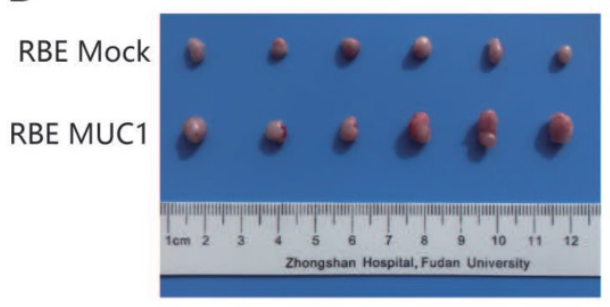

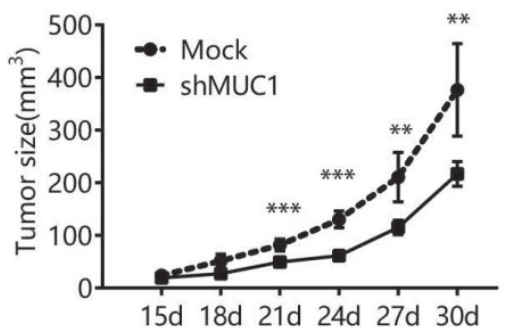

$15 \mathrm{~d} 18 \mathrm{~d} 21 \mathrm{~d} 24 \mathrm{~d} 27 \mathrm{~d} 30 \mathrm{~d}$

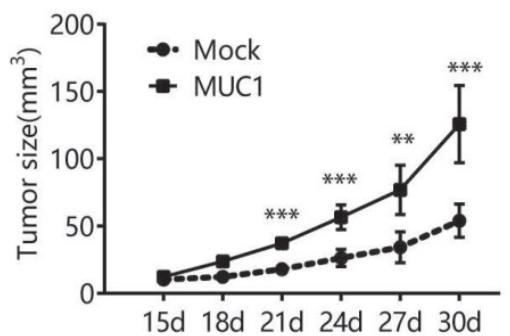

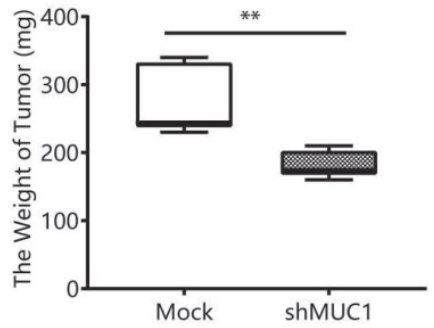

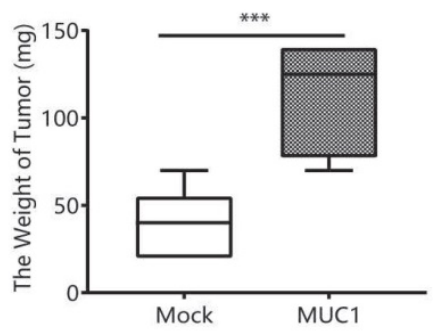

Figure 3. Up-regulation of MUCl promoted ICC progression in vivo. A and B. Effects of MUCl overexpression and down-regulation on the growth of in vivo subcutaneous xenograft tumors. Tumor volume and weight of xenografts derived from HCCC9810-shMUC1 cells were significantly reduced as compared with those of tumors derived from HCCC9810-Mock cells $(n=6)$; tumor volume and weight of xenografts derived from RBE-MUC1 cells were markedly increased as compared with those of tumors derived from RBE-Mock cells $(n=6)$. All bar graphs depicted quantification of triplicate results with mean \pm SD. $* * P<0.01$, and $* * * P<0.001$.

\section{Discussion}

ICC refers to a cholangiocarcinoma originating from peripheral bile ducts within the liver parenchyma and is distinguished from perihilar cholangiocarcinoma as well as distal cholangiocarcinoma [28]. It accounts for approximately 5\% to $10 \%$ of cholangiocarcinoma with dismal clinical outcome [29]. The unsatisfying clinical outcomes might be a result of the high invasive feature of ICC including multifocal growth, regional lymph node metastasis and vascular invasions which all leading to poor long-term survival and short-term recurrence after resection [30].

Mucin 1 (MUC1) is a transmembrane glycoprotein that is aberrantly unregulated in numerous types of cancers, and serves as a key oncogene in the tumorigenesis of various human adenocarcinomas [31,32]. However, the role of MUC1 in ICC progression as well as its potential mechanism remains poorly understood. Similarly as what had been proved in our previous study and other types of cancers [16,33-37], our data showed that the expression of MUC1 protein was significantly up-regulated in ICC tissues. More importantly, our results indicated that ICC patients with high MUC1 protein expression were associated with worse prognosis compared to those with low MUC1 protein expression. Notably, high protein expression of MUC1 was associated with more progressive clinical features such as larger tumor size, presence of lymphatic metastasis, advanced tumor stage, vascular invasion [28,38]. In addition, the importance of MUC1 expression was similar among patients with low recurrent risk groups. Furthermore, our data also showed that knockdown of MUC1 expression could significantly suppressed tumor cell proliferation, invasion, migration, and cell cycle progression in vitro, and could significantly inhibit tumor growth in mouse subcutaneous xenograft model. Therefore, we believe that MUC1 plays an important role in tumor progression and might be a novel therapeutic target for ICC treatment.

It is well-known that the most ICC patients were associated with poor prognosis [28]. It is very important to predict the risk of recurrence for timely postoperative adjuvant therapy to improve the prognosis of ICC patients [39]. However, it is hard to predict which individual will have tumor relapse after surgical treatment for ICC patients [40]. Our data showed that MUC1 was an independent predictor for overall survival and relapse-free survival after tumor resection. Furthermore, the prognostic significance of MUC1 was reconfirmed in the ICC subgroups with low recurrent risk (Figure S1), such as CA199 level $<37 \mathrm{U} / \mathrm{ml}$, Tumor size $\leq 5 \mathrm{~cm}$, without lymphatic metastasis, without vascular invasion and TNM stage I $[29,40]$. Thus, MUC1 might be a candidate biomarker for prognosis prediction of ICC patients.

To explore the potential mechanism of MUC1 in ICC, we further performed high-throughput mRNA transcriptome sequencing on surgical specimens of 10 ICC patients and found that the Wnt signaling pathway was significantly enriched in ICC tissues based on the KEGG enrichment analysis (Figure 4B). According to GSEA analysis [41], we also found that 
MUC1 plays an important role in the Wnt signaling pathway (Figure 4C). Interestingly, we found that the expression levels of $\beta$-catenin changed significantly with the expression level of MUC1 (Figure S2). Furthermore, the results from Western blot analysis also confirmed that the expressions of $\beta$-catenin as well as the key downstream genes (Cyclin D1, c-Myc, and MMP-7) in the Wnt/ $\beta$-catenin signaling pathway were significantly affected by knockdown or overexpression of MUC1 in two ICC cell lines $[25-27,42]$. Taken together, our data indicate that MUC1 might regulate $\mathrm{Wnt} / \beta$-catenin signaling pathways to exert their tumor-activating functions in ICC (Figure 5). However, the detailed upstream mechanism of MUC1 regulation in ICC remains to be further explored.

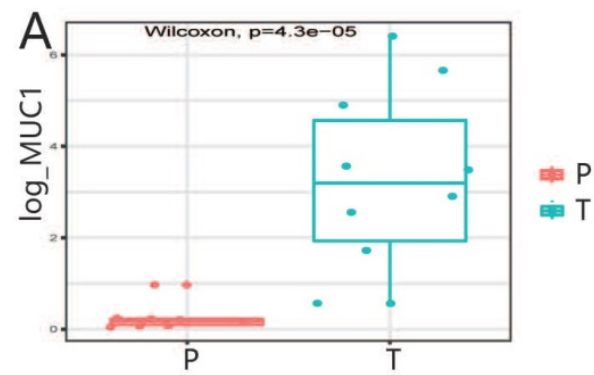

B
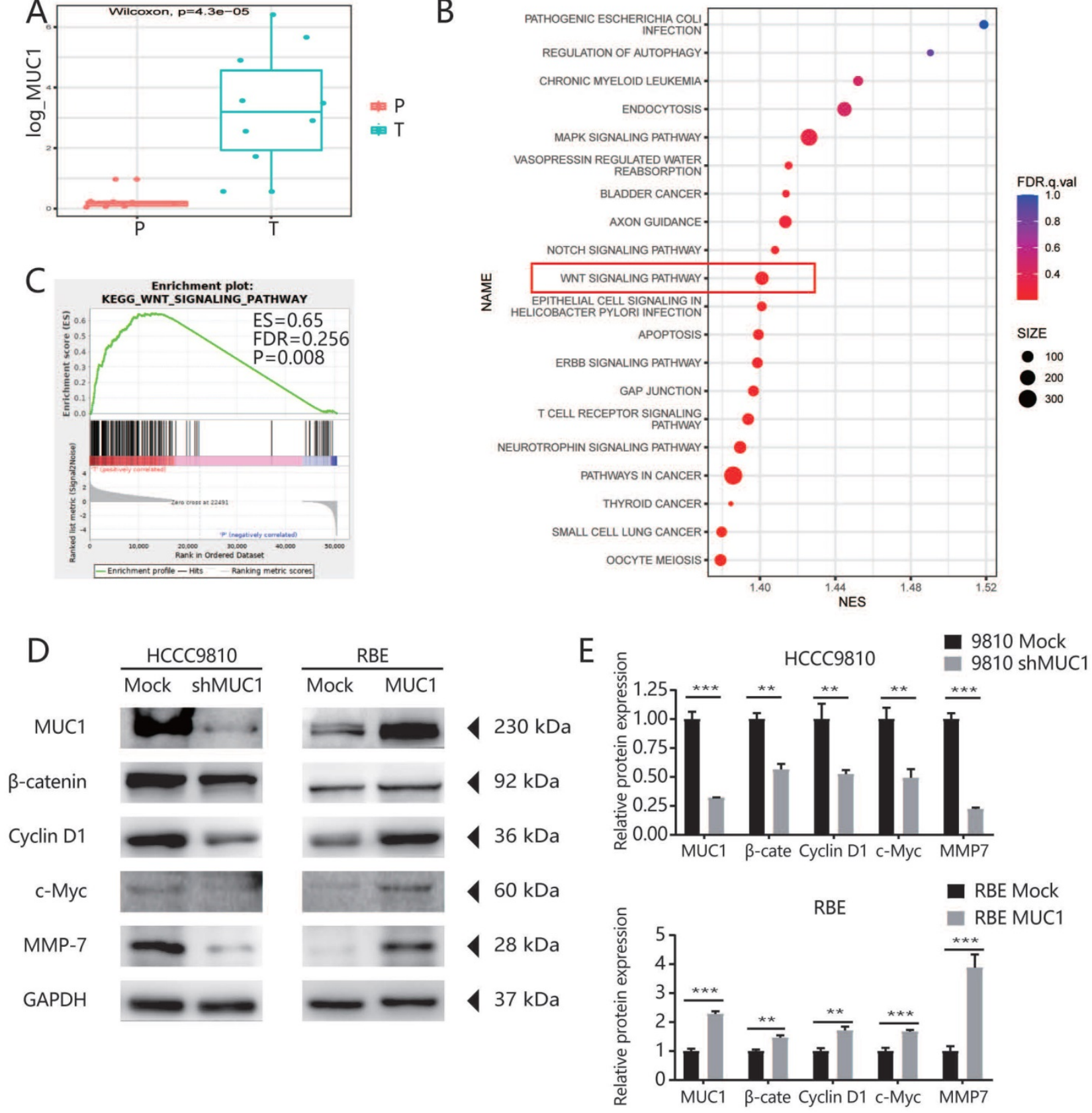

Figure 4. MUCI regulated ICC cell proliferation, cell cycle progression, and invasive potential through the Wnt/ $\mathbf{W}-\mathrm{catenin}$ signaling pathway. A. Highthroughput mRNA transcriptome sequencing was performed on 10 pairs of cancer tissues and adjacent tissues of ICC patients. In these sequencing samples, the mRNA expression level of MUCl in the corresponding tumor tissues and adjacent tissues was subjected to paired T test. B. KEGG enrichment analysis based on these differentially expressed genes. C. GSEA analysis of WNT signaling pathway based on the gene expression profiles of high MUCl group (red) versus low MUCl group (blue) in our sequencing samples, ES, enrichment score; FDR, false discovery rate value. D. The expression level of related proteins in the Wnt/ $\mathrm{B}-\mathrm{catenin}$ signaling pathway, such as Cyclin DI, c-Myc, MMP-7, $\beta$-catenin and MUCl were compared in indicated cells. GAPDH was used as loading control. E. Densitometry analysis was performed on three experiments representative of $\mathrm{B}$ and expressed relative to GAPDH or the corresponding total protein as the internal control. 


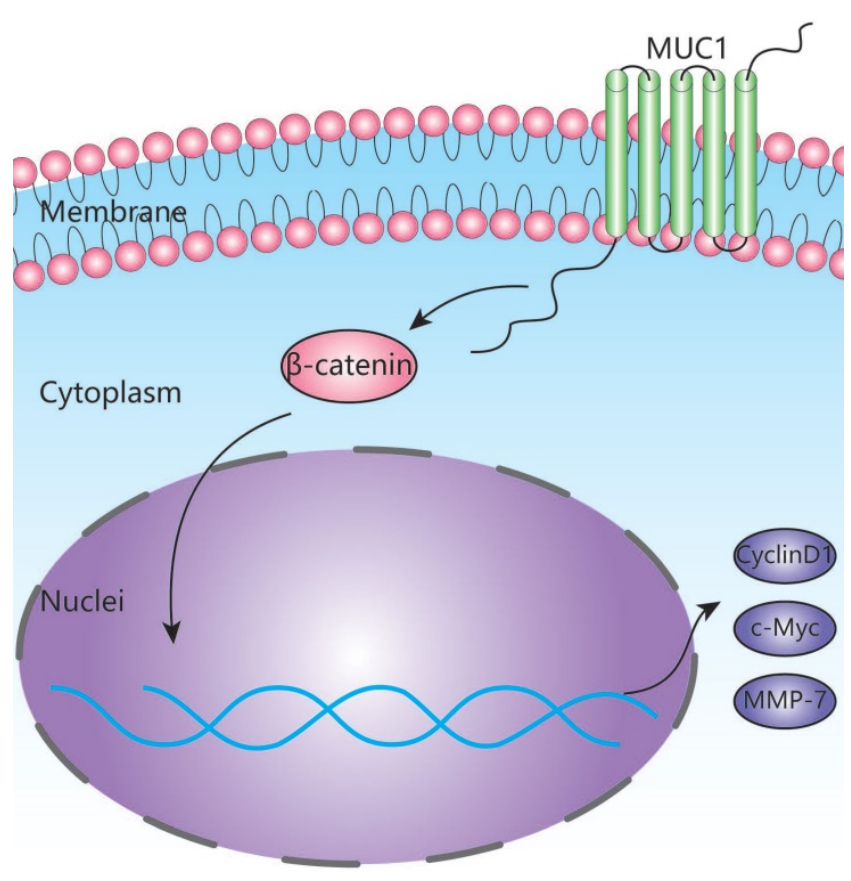

Figure 5. Schematic depiction of the mechanism underlying MUC1-mediated Wnt/ $\mathrm{W}$-catenin signaling pathway activation and ICC metastasis.

This study has several limitations. First, this was a retrospective study from a single medical center which needs to be further validated in a large-scale, prospective, multicenter study. Meanwhile, although the association between MUC1 and Wnt/ $\beta$-catenin signaling pathway was observed, how MUC1 triggers Wnt/ $\beta$-catenin signaling activation is still unsolved and need to be further clarified.

In summary, our research shows that MUC1 is often up-regulated in ICC and promotes tumor progression by activating the Wnt/ $\beta$-catenin signaling pathway. Importantly, the down-regulation of MUC1 significantly inhibited the proliferation and invasion of ICC. This study not only explored the pathogenesis, but also shed light upon identifying new therapeutic targets for ICC.

\section{Abbreviations}

ICC: intrahepatic cholangiocarcinoma; MUC1: Mucin1; CCK8: Cell Counting Kit-8; TMA: tissue microarrays analysis; TNM: tumor-node-metastasis; FCM: flow cytometry; FBS: fetal bovine serum; ES: enrichment score; FDR: false discovery rate value; NES: Normalized Enrichment Score; $\beta$-catenin: catenin beta interacting protein 1; c-Myc: MYC proto-oncogene; KEGG: Kyoto Encyclopedia of Genes and Genomes; MMP-7: matrix metallopeptidase 7; FPKM: Fragments Per Kilobase of exon model per Million mapped fragments; GAPDH: glyceraldehyde 3-phosphate dehydrogenase; PI: propidium iodide.

\section{Supplementary Material}

Supplementary figures and table.

http://www.jcancer.org/v12p6937s1.pdf

\section{Acknowledgements}

This study was supported by the National Key Research and Development Program grants (2016YFF0101405, 2019YFC1315800, 2019YFC1315802), the State Key Program of National Natural Science of China grants (81530077, 81830102), the National Natural Science Foundation of China grants (81602543, 81672839, 81572823, 81772578, 81772551, and 81872355), the Strategic Priority Research Program of the Chinese Academy of Sciences grants (XDA12020105 and XDA12020103), the Shanghai Municipal Health Commission Collaborative Innovation Cluster Project (2019CXJQ02), the Shanghai Rising-Star Program Funding Program from the Shanghai Science and Technology Commission (19QA1402000), Shanghai "Rising Stars of Medical Talent" Youth Development Program (Outstanding Youth Medical Talents), the Projects from the Shanghai Science and Technology Commission (19441905000), Shanghai Municipal Key Clinical Specialty.

\section{Ethics approval and consent to participate}

Ethical approval was given by the Ethics Committee of Zhong Shan Hospital, and informed consent was obtained from each patient.

\section{Competing Interests}

The authors have declared that no competing interest exists.

\section{References}

1. Bridgewater J, Galle PR, Khan SA, et al. Guidelines for the diagnosis and management of intrahepatic cholangiocarcinoma. Journal of hepatology. 2014; 60(6):1268-1289.

2. Yang JD, Kim B, Sanderson SO, et al. Biliary tract cancers in olmsted county, minnesota, 1976-2008. Am J Gastroenterol. 2012; 107(8):1256-1262.

3. Njei B. Changing pattern of epidemiology in intrahepatic cholangiocarcinoma. Hepatology. 2014; 60(3):1107-1108.

4. Patel T. Increasing incidence and mortality of primary intrahepatic cholangiocarcinoma in the united states. Hepatology. 2001; 33(6):1353-1357.

5. Hanisch FG. O-glycosylation of the mucin type. Biol Chem. 2001; 382(2):143-149.

6. Corfield A. Eukaryotic protein glycosylation: A primer for histochemists and cell biologists. Histochem Cell Biol. 2017; 147(2):119-147.

7. Moniaux N, Escande F, Porchet $\mathrm{N}$, et al. Structural organization and classification of the human mucin genes. Front Biosci. 2001; 6(D1192-1206.

8. Andrianifahanana M, Moniaux N, Batra SK. Regulation of mucin expression: Mechanistic aspects and implications for cancer and inflammatory diseases. Biochim Biophys Acta. 2006; 1765(2):189-222.

9. Seregni E, Botti C, Massaron S, et al. Structure, function and gene expression of epithelial mucins. Tumori. 1997; 83(3):625-632.

10. Johansson ME, Sjovall H, Hansson GC. The gastrointestinal mucus system in health and disease. Nature reviews Gastroenterology \& hepatology. 2013; 10(6):352-361.

11. Dhanisha SS, Guruvayoorappan C, Drishya S, et al. Mucins: Structural diversity, biosynthesis, its role in pathogenesis and as possible therapeutic targets. Crit Rev Oncol Hematol. 2018; 122(98-122.

12. Strous GJ, Dekker J. Mucin-type glycoproteins. Crit Rev Biochem Mol Biol. 1992; 27(1-2):57-92. 
13. Zhan XX, Zhao B, Diao C, et al. Expression of muc1 and cd176 (thomsenfriedenreich antigen) in papillary thyroid carcinomas. Endocr Pathol. 2015; 26(1):21-26.

14. Jing $\mathrm{X}$, Liang $\mathrm{H}, \mathrm{Hao} \mathrm{C}$, et al. Overexpression of muc1 predicts poor prognosis in patients with breast cancer. Oncol Rep. 2019; 41(2):801-810.

15. Niv Y. Muc1 and colorectal cancer pathophysiology considerations. World J Gastroenterol. 2008; 14(14):2139-2141.

16. Chen FY, Zhou C, Zhang XY, et al. Integrated Bioinformatics analysis and clinical validation reveals that high expression of mucin 1 in intrahepatic cholangiocarcinoma predicts recurrence after curative resection. Exp Ther Med. 2020; 20(5):50.

17. Ronnekleiv-Kelly SM, Pawlik TM. Staging of intrahepatic cholangiocarcinoma. Hepatobiliary Surg Nutr. 2017; 6(1):35-43.

18. Chen XX, Yin Y, Cheng JW, et al. Bap1 acts as a tumor suppressor in intrahepatic cholangiocarcinoma by modulating the erk1/2 and jnk/c-jun pathways. Cell Death Dis. 2018; 9(10):1036.

19. Gao Q, Zhao YJ, Wang XY, et al. Activating mutations in ptpn3 promote cholangiocarcinoma cell proliferation and migration and are associated with tumor recurrence in patients. Gastroenterology. 2014; 146(5):1397-1407.

20. Yang LX, Gao Q, Shi JY, et al. Mitogen-activated protein kinase kinase kinase 4 deficiency in intrahepatic cholangiocarcinoma leads to invasive growth and epithelial-mesenchymal transition. Hepatology. 2015; 62(6):1804-1816.

21. Hu B, Cheng JW, Hu JW, et al. Kpna3 confers sorafenib resistance to advanced hepatocellular carcinoma via twist regulated epithelial-mesenchymal transition. J Cancer. 2019; 10(17):3914-3925.

22. Samatar AA, Poulikakos PI. Targeting ras-erk signalling in cancer: Promises and challenges. Nat Rev Drug Discov. 2014; 13(12):928-942.

23. Clevers H, Nusse R. Wnt/beta-catenin signaling and disease. Cell. 2012; 149(6):1192-1205.

24. Wodarz A, Nusse R. Mechanisms of wnt signaling in development. Annu Rev Cell Dev Biol. 1998; 14(59-88.

25. Brabletz T, Jung A, Dag S, et al. Beta-catenin regulates the expression of the matrix metalloproteinase-7 in human colorectal cancer. Am J Pathol. 1999; 155(4):1033-1038.

26. Wilkins JA, Sansom OJ. C-myc is a critical mediator of the phenotypes of apc loss in the intestine. Cancer Res. 2008; 68(13):4963-4966.

27. Shtutman M, Zhurinsky J, Simcha I, et al. The cyclin d1 gene is a target of the beta-catenin/lef-1 pathway. Proc Natl Acad Sci U S A. 1999; 96(10):5522-5527.

28. Zhang $\mathrm{H}, \mathrm{Yang} \mathrm{T}, \mathrm{Wu} \mathrm{M}$, et al. Intrahepatic cholangiocarcinoma: Epidemiology, risk factors, diagnosis and surgical management. Cancer Lett. 2016; 379(2):198-205.

29. Mavros MN, Economopoulos KP, Alexiou VG, et al. Treatment and prognosis for patients with intrahepatic cholangiocarcinoma: Systematic review and meta-analysis. JAMA Surg. 2014; 149(6):565-574.

30. Wang Y, Li J, Xia Y, et al. Prognostic nomogram for intrahepatic cholangiocarcinoma after partial hepatectomy. J Clin Oncol. 2013; 31(9):1188-1195.

31. Retterspitz MF, Monig SP, Schreckenberg S, et al. Expression of \{beta\}-catenin, muc1 and c-met in diffuse-type gastric carcinomas: Correlations with tumour progression and prognosis. Anticancer Res. 2010; 30(11):4635-4641.

32. Khodarev N, Ahmad R, Rajabi H, et al. Cooperativity of the muc1 oncoprotein and stat1 pathway in poor prognosis human breast cancer. Oncogene. 2010; 29(6):920-929.

33. Budiu RA, Mantia-Smaldone G, Elishaev E, et al. Soluble muc1 and serum muc1-specific antibodies are potential prognostic biomarkers for platinumresistant ovarian cancer. Cancer Immunol Immunother. 2011; 60(7):975-984.

34. Yonezawa S, Kitajima S, Higashi M, et al. A novel anti-muc1 antibody against the muc1 cytoplasmic tail domain: Use in sensitive identification of poorly differentiated cells in adenocarcinoma of the stomach. Gastric Cancer. 2012; 15(4):370-381.

35. Zhang K, Tang $\mathrm{W}, \mathrm{Qu}$ X, et al. Kl-6 mucin in metastatic liver cancer tissues from primary colorectal carcinoma. Hepatogastroenterology. 2009; 56(93):960-963.

36. $\mathrm{Xu} \mathrm{H}$, Inagaki $\mathrm{Y}$, Seyama $\mathrm{Y}$, et al. Expression of kl-6/muc1 in pancreatic cancer tissues and its potential involvement in tumor metastasis. Oncol Rep. 2011; 26(2):371-376.

37. Gao J, McConnell MJ, Yu B, et al. Muc1 is a downstream target of stat3 and regulates lung cancer cell survival and invasion. Int J Oncol. 2009; 35(2):337-345.

38. Ribero D, Pinna AD, Guglielmi A, et al. Surgical approach for long-term survival of patients with intrahepatic cholangiocarcinoma: A multiinstitutional analysis of 434 patients. Arch Surg. 2012; 147(12):1107-1113.

39. Tsilimigras DI, Sahara $\mathrm{K}, \mathrm{Wu} \mathrm{L}$, et al. Very early recurrence after liver resection for intrahepatic cholangiocarcinoma: Considering alternative treatment approaches. JAMA Surg. 2020; 155(9):823-831.

40. Hyder $\mathrm{O}$, Marques $\mathrm{H}$, Pulitano $\mathrm{C}$, et al. A nomogram to predict long-term survival after resection for intrahepatic cholangiocarcinoma: An eastern and western experience. JAMA Surg. 2014; 149(5):432-438.

41. Reimand J, Isserlin R, Voisin V, et al. Pathway enrichment analysis and visualization of omics data using g:Profiler, gsea, cytoscape and enrichmentmap. Nat Protoc. 2019; 14(2):482-517.

42. Mann B, Gelos M, Siedow A, et al. Target genes of beta-catenin-t cell-factor/ lymphoid-enhancer-factor signaling in human colorectal carcinomas. Proceedings of the National Academy of Sciences of the United States of America. 1999. 96(4):1603-1608 